\title{
FERNANDO LAZARO
}
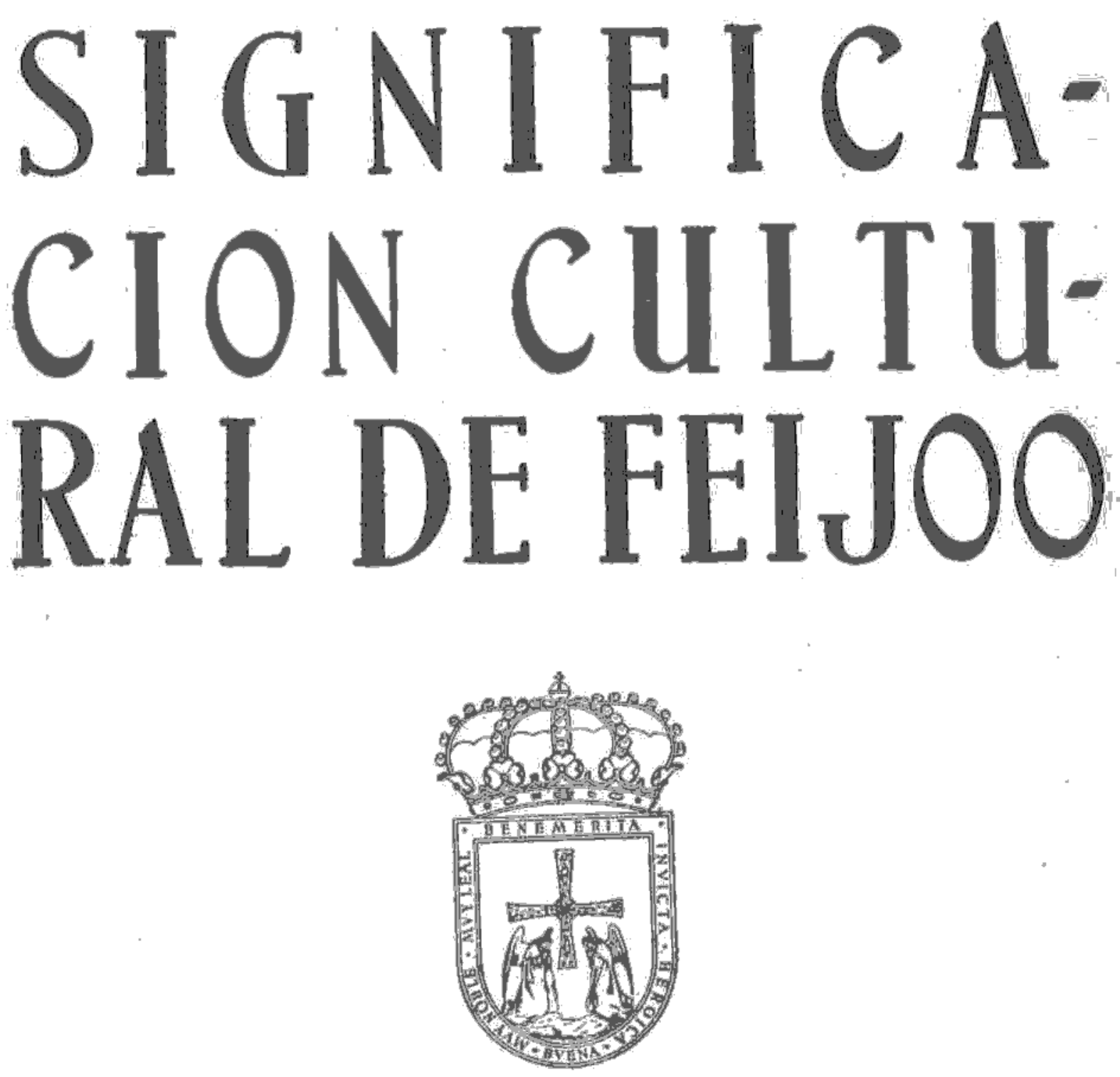

CUADERNOS DE LA CATEDRA FEIJOO INSTTUUIDA POR EL EXCMO.AYUNTAMIENTO DE OVIEDO EN LA UNIVERS IDAD

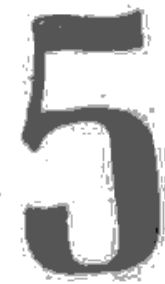


FERNANDO LAZARO CARRETER

S I G N I F I C A C I O N

CULTURAL DE FEIJOO

I957 

FAmOSA es la escena que glosó de modo magistral D. Gregorio Marañón ${ }^{(x)}$ : El P. Feijóo, una noche de otoño, pasea por su celda; quizá para buscar reposo y frescor a su mente, se ha acercado a la abierta ventana; fuera una espesa niebla promete ya un invierno cierto. Fr. Benito, con la cabeza preocupada por Dios sabe qué obsesiones, ha clavado sus ojos distraídos en la niebla densa y blanda; $y$, de pronto, el prodigio: el vengador de tantos íncubos y súcubos, de tantos duendes y fantasmas combatidos por su pluma implacable, está allí; es un descomunal gigante, "un formidable espectro", plantado frente a él, con gesto de desafío. Todo el espanto precipitándose a sus piernas le incita a huir, a

1. G. Maranón, Las ideas biológieas dol P. Fefjón, Madrid, Espasa-Calpe, 1934, págs. 64 y s. Se narra eate hecho en TC, V, 1, 44. Nota 5, a. 
confesar su vencimiento, su sometimiento a la superstición. Pero he aquí que el corazón se impone y el cerebro comienza a examinar los hechos. Todo aquello tendrá alguna razón natural, y la tiene: el terrorífico aparecido no es otro... que el propio Feijóo, por mejor decir, su sombra proyectada contra la espesa niebla. No hay la menor duda: si el buen monje eleva un brazo, el "espectro" alza el suyo; y permanece inmóvil, quieto, inofensivo, mientras Fr. Benito se reconcentra para que su pulso recupere el tono y sus piernas se sustraigan al estremezón. Es sólo un minuto; enseguida su mente comienza a funcionar y a establecer proporciones matemáticas entre las distancias y magnitudes del cuerpo y su sombra. El terror ha sido vencido por la física, el misterio ha sucumbido ante la razón natural.

Diez años antes, poco más o menos, otro gran escritor de este momento, el salmantino Diego de Torres Villarroel, luego catedrático de Matemáticas de aquella vieja Universidad, ha sido protagonista de otro suceso mágico, si bien de proporciones más escandalosas y cómicas que el acontecido ante la ventana del benedictino. Merece la pena que lo recordemos, para obtener por contraste algunos puntos definidores de Feijóo. Don Diego andaba siempre a vueltas con los misteriosos habitantes del más allá; creía en ellos sin creer, y aparentaba despreocuparse, cuando en realidad estaba preocupado. "No he de ser tan desgraciado-aseguraba-que me toque a mí la mala ventura" ${ }^{(a)}$. Pero al pícaro doctor le tocó una vez la mala, la pésima ventura, y el pobre corrió, tembló y trasudó de miedo. Un aciago día yendo por la madrileña calle de Atocha, D. Diego oyó de labios del capellán de la condesa de Arcos una

2. Torres Villarroel, Vida, ed. de F. de Onis. Madeld, Clás. Cast. 1941, pág. 72. 
espeluznante historia: la señora condesa y su servidumbre andaban confusos y atribulados por los golpes tremendos que, desde hacía tres noches, venían oyéndose "en todos los centros y extremidades de las piezas de la casan. El doctor, requerido por el capellán para prestar amparo a su señora, hizo de tripas vacías corazón esforzado, y marchó a pasar la noche al palacio de la condesa. Todo era en él desolación; en una sala se habían concentrado todas las camas, y la señora y los criados, con la nivelación igualitaria que produce el miedo, se disponían a afrontar una nueva noche de horror. Nuestro doctor, con una luz próxima y una espada oxidada a mano, se puso a dormir. Pero a la una se dejaron oir los alucinantes golpes. Entre gritos y ayes, comenzó D. Diego la pesquisa. Habitación tras habitación, todo el palacio fué sometido a examen; pero, cada cuarto de hora, el estruendo se producía sin dejarse sorprender la causa. Todo cesó a las tres y media, y aquel emparedado de carne temblorosa que era la sala comunal, y su defensor Torres, pudieron al fin añadir el descanso al temor. Once noches duraron estos terrores, aumentados por las fracasadas exploraciones del pícaro salmantino, y al fin, la última que la asediada tropa pudo resistir en el palacio, todo culminó. Sonaron, efectivamente, en el techo del gran dormitorio unos golpecillos como de provocación, y D. Diego acudió pronto al lance. Subió al aposento de donde procedían los ruidos, pero al entrar le apagaron el hacha de cuatro pabilos con que se alumbraba, y resonaron cuatro descomunales golpes, que removieron el palacio hasta el punto de derribar los cuadros de las paredes. Ah, el buen Torres, que medio creía sólo en la fauna sepulcral, comprendió en aquel trance cuán imprudente era su escepticismo: "Inmóvil y sin uso en la lengua-nos con- 
fiesa-me tiré al suelo, y ganando en cuatro pies las distancias, después de largos rodeos, pude atinar con la escalera. Levanté mi figura, y aunque poseído del horror, me quedó la advertencia para bajar a un patio, y en su fuente me Chapucé, y recobré algún poco del sobresalto y el temor" ${ }^{(3)}$. Torres suplicó a la despavorida condesa que lo liberase de la custodia y al siguiente día, todos, su excelencia y D. Diego, convertido de paladín en gorrón, acompañados de los criados, abandonaron el palacio encantado de la calle de Fuencarral y marcharon a la del $\mathrm{Pez}$, a dar reposo a los ánimos en una casa menos retumbadora.

Feijóo y Torres son rigurosamente contemporáneos. El doctor tenía diez y siete años menos que el monje, si bien en la muerte anduvieron más parejos, ya que Fr. Benito murió en 1764 y D. Diego seis años después, en 1770 . Y, sin embargo, entre ambos eminentes escritores median abismos diferenciales, a pesar de ser legítimos hijos de su siglo los dos. Uno posee mente mágica; el otro somete todo al filo de la razón. Feijóo, asceta y sabio, se recluye en su celda-estudio y sus obras maduran en el silencio. Torres, por el contrario, dice de sus escritos: «Los más de ellos los he parido entre cabriolas y guitarras, sobre el arcón de la cebada de los mesones, oyendo los gritos, Chanzas, desvergüenzas y pullas de los caleseros, mozos de mulas y caminantes" (4). El benedictino dará paz a muchas almas negando los influjos astrológicos en la suerte de los hombres, mientras el catedrático se enriquece leyendo en los astros sus pronósticos. El Padre Maestro arremete contra duendes, brujas y trasgos; D. Diego, por el contrario,

3. Ibid., pags, 92-93.

4. El ermittâno J Torres, vol. VI, pág. 38 de la ed. de las obras completas publicadas entre 1794.1799. 
clasificará formalmente los demonios en ígneos, aéreos, térreos, caseros, montanos y silvestres. El primero adopta la niveladora forma europea del ensayo para comunicarse con el lector; el segundo finge sueños, al modo quevedesco, para describirnos los prodigios de la digestión o las maravillas del subsuelo. El enfermo es para el monje un objeto de consideración médica; para el doctor, un punto de meditación en nuestra humana miseria. Feijóo habla de la enfermedad como un doctor; el doctor lo hace como un fraile. Uno separa naturaleza y sobrenaturaleza en sus meditaciones, con el rigor de un sabio y la pulcritud de un creyente: el otro mezcla ambos reinos y sus obras se titulan Anatomía de lo visible e invisible de ambas esferas y viaje fantástico, Los desabuciados del mundo y de la Gloria o Vida natural y católica.

¿Qué zona hay, pues, de paridad entre ambos ingenios que justifique nuestra aserción anterior, a saber, la de que son los dos hijos representativos de su siglo? $\mathrm{Si}$ a las relaciones entre ambos atendemos, aún hemos de hallar menos apoyo para la prueba. Cuando Torres Villarroel, que obtenía pingües ingresos como oráculo con su Gran Piscator de Salamanca, se sintió aludido por la furia con que Fr. Benito arremetió contra estas astrologías en el tomo I de su Teatro crítico universal, se limitó a callar porque, decía, chanceramente, en una carta publicada pocos meses después, "me aconsejó mi buena crianza que no hay contra un padre razón"; y al defenderse de ataques semejantes, provenientes ahora de Martín Martínez, el famoso médico amigo de Feijóo, se volvió contra éste, asegurando que para verse libre del silencio que la regla le imponía, se dedicaba a alborotar en la república de las letras, manteniendo «en cuestión los ingenios, en borrasca los discursos y en 
pendencias y pleitos los ánimos" ${ }^{(5)}$. No fueron pocas las veces que los dos hicieron correr con mutuo acaloramiento sus plumas, armado el benedictino de razón y de ingenio el doctor.

$\mathrm{Y}$ sin embargo, cuando nos metemos por entre medio del alboroto para ver si tienen algo de común bajo tanta diferencia, hallamos de pronto que los dos, con distintas armas, con diferente actitud y formación, hasta con diversos ideales, han partido de una misma trinchera, de un idéntico pesimismo ante la realidad nacional que les toca vivir. Por eso los vemos fustigando, el uno desde su Teatro, la ambición política, la ociosidad, la justicia venal, el interés de los clérigos, el patrioterismo, los petimetres, los puristas y la ignorancia en sus plurales manifestaciones ${ }^{(6)}$; y el otro desde muChas de sus obras, pero sobre todo desde la titulada Visiones y visitas de D. Francisco de Quevedo por la Corte, la ceguera intelectual de las universidades, la frivolidad de las mujeres, la disolución y destemplanza de los hombres, la falta de devoción, la zafiedad de las costumbres, la miseria de la poesía, la cual, asegura, después de andar de taberna en taberna, "vino a depositar sus huesos en el carnero de un hospital". Son muchas las coincidencias que, en el plano satírico, muestran ambos escritores; pero su amplitud no se extiende a más. Sólo por afán paradójico se explica el que crítico tan versado en la obra feijoniana como M. Delpy haya podido escribir que, si bien es imposible confundir a uno con el otro, "ils se completent beaucoup

5. Apud A. Millares, en su excelente prologo al tomo I de las Obras de Feljoo, Madrid Clás. Cast., 1923, págs. 23 y ss.

6. Cft. Marañón, op.. cit., paga. 76 y ss. 
plus qu'ils ne se contradisent et ne s'opposent" (7). ¿Ocurrirá sin embargo que las oposiciones o concordancias que entre Feijóo y Torres puedan establecerse sean un mero azar, fruto de sus caracteres respectivos? Si así fuera, contrastarlos sólo tendría un interés anecdótico. Pero no creemos en esta posibilidad; por el contrario, los dos con su preocupación enciclopédica y su mutua irritabilidad, nos parecen máximos representantes de dos fuerzas antagónicas que, al chocar a principios del siglo XVIII, producen la más importante crisis cultural de nuestra historia. Será necesario, por tanto, que definamos en sus líneas más salientes las razones de aquella crisis para poder "situar» cumplidamente a Feijóo.

Pará ello, hemos de remontarnos algo, en pos de unos hilos que ahora, hacia 1700 , van a entramarse de otro modo. Hemos de llegar al Renacimiento, para encontrar sus cabos en la honda revolución que allí se opera. Consiste ésta, sobre todo, en una radical escisión entre la naturaleza y la sobrenaturaleza, entre el mundo de los sentidos y los supuestos religiosos, tan íntimamente fundidos ambos en el hombre medieval. Recordemos aquel inextricable Libro de buen amor, en el que a veces, siguiendo el hilo de una moralidad caemos en un lozano lugar y, por el contrario, en medio de una garbosa ligereza nos asalta la meditación de ultratumba.

7. G. Delpy, L' Eapağne et $l^{\prime}$ esprit européen. L'eeurre de Feijöa. Paris, Hachetre, ?936, página 276. Es clerto que, en El ermiteño y Torres, ed. cit., págs, 36 y ss. hace decir al primero: Aquit tengo muchos de los escritos que se publicaron contra el Teatro eritivo universel, y es cierto que habléndolos pesado con reflexlón, en muy pocos... encontré que sus autores se manifestasen a lo menos instruidos en las reglas de la gramática castellana. Dejo aparte los reparos justos y debilísimos argumentos con que intentaron desacreditar la crítica del monje (Fejjoo), impugnando sus sentencias y paradojas. En aquel tiempo-le respondi-se metio a escritor todo sal. vaje y arí salieron al mundo impresas muchas bestialidades otensivas de los oídos discretos". Pero como M. Delpy nota, Torres, más que elogiar al Padre Maestro, lo que hace es condenar a sus contradictores. Por otra parte, si algo no puede negarse al catedrático salmantino es nobleza de corazon. 
El Renacimiento fué, ante todo, un colosal esfuerzo para desenmarañar tanta confusión, para separar cielo y tierra. La Celestina, con su humano, demasiado humano carácter, sería una obra plenamente renacentista, si, al final, la Providencia no interviniera para castigar tanto loco amor, tanto pecado. Pero ya es de la nueva época el Lazarillo de Tormes, esa genial aventura por los reinos bien terrenales del hambre. Si Santillana escribe versos a la amada, moralidades y cánticos devotos, Garcilaso reservará su pluma para cantar únicamente ternezas de enamorado, mientras que, en el otro polo, los celestes juglares, San Juan o Santa Teresa, niegan su lira a los sentidos, ansiosos únicamente de divinidad. Este hercúleo esfuerzo del hombre para deslindar en su espíritu las antes confusísimas fronteras, produce de un lado el apogeo de la mística y la ascética, y, de otro, el desarrollo de las ciencias naturales, la investigación racional del mundo.

Pero he aquí que, dado el impulso discriminatorio, las consecuencias llegaron a extremos impensados. Tanto se apartó el hombre de la Divinidad, que allá en Ginebra, Juan Calvino predicaba una doctrina que iba prendiendo como la pólvora en las almas. Según ella, el hombre y Dios eran dos incomunicables soledades. La criatura nada podía influir con su comportamiento en las decisiones inescrutables del Creador, el cual concedía su Gracia y la salvación a unos cuantos elegidos. Europa se escinde, con la disputa de la predestinación y el libre albedrío, en dos dramáticas e irreconciliables mitades. Roma acudió con relativa presteza a su propia defensa, en Trento, y nuestros teólogos tuvieron que poner su dialéctica al servicio de una más íntima religación del hombre y Dios. Las consecuencias de Trento son incalculables para nuestra cultura. Si allí que- 
dó exenta España de la herejía, también allí fué sellado el porvenir inmediato de la cultura española. De nuevo, naturaleza y sobrenaturaleza tendieron a acercarse y la pesquisición científica que omitiera lo trascendente fué mirada como suspecta ${ }^{(8)}$. Si el Lazarillo era un símbolo del espíritu renaciente, su sucesor el Guzmán de Alfarache, con su brutal mundanidad ensartada en un sermonario moral, es ya un fruto típico del nuevo espíritu que se ha dado en calificar de barroco. Y si Garcilaso y San Juan eran extremos líricos del quinientos-amor humano el uno y amor divino el otro--, el genio nuevo, Lope de Vega, funde en su corazón ambos amores, y es a la vez, sacrílego' y asceta, múltiple galán y místico solitario. De semejante modo, otro prohombre del barroco, Francisco de Quevedo, mezclará tierra y cielo en sus burlas y en sus veras. El extremo no ya herético sino burdamente pecador de esta fusión podemos descubrirlo, por ejemplo, en las aberraciones del convento de San Plácido, en las que la mística andaba a vueltas con la torpeza carnal. La Inquisición acudió al frente en que el curso de los acontecimientos la reclamaba y mantuvo su ojo alerta en ese punto indisoluble en que Gracia y Naturaleza se tocaban. Todo, pensamiento u obras, que quisieran acogerse a uno de estos reinos con olvido del otro, fué proscrito, y ello originó, como reacciones secundarias, de un lado, la timidez de la ciencia española, que se descompensa en relación con el ritmo extranjero, y de otro, como reacción patológica hacia el contrario extremo, esas monstruosas imbricaciomes que acabamos de señalar. Por la época en que Galileo, Copérnico y Kepler dotaban al

8. Utilizo en buena parte de eata exposición las fecundas ideas de E. Tierno Galván en su ensayo Notas sobre el barreco, Murcia, 1955. 
mundo de leyes naturales y matemáticas, España alumbraba frutos asombrosos para el arte, pero quedaba al margen de aquellas inquietudes. "Desde el punto de vista de la historia cultural-ha escrito Karl Vossler - es apenas posible imaginarse una cisura más violenta que la diferencia que seabre aquí entre España y Europa" ${ }^{(9)} \mathrm{Y}$ Julio Rey Pastor comenta con desolación: "Los más genuinos representantes de la matemática española en el período en que Vieta, Descartes, Fermat y Pascal asombran al mundo, son libros de cuentas y geometrías de sastres» ${ }^{(x)}$. Podrá defenderse desde la conveniencia religiosa que esto ocurriera así; lo que no se podrá hacer es negarlo. El generoso empeño de Don Marcelino Menéndez Pelayo en mostrar un panorama halagüeño en este punto, tiene más de quijotesca bizarría que de convincente hazaña.

Evidentemente el pensamiento científico español se retrajo hasta casi la inexistencia. Se dirá que los límites puestos por los guardianes de la ortodoxia eran muy amplios, y que dentro cabía con holgura la especulación naturalista. Esto es evidente; pero la más grave acción inhibidora que toda vigilancia ejerce, no es tanto sobre lo que llega a sus manos y, si se quiere, hasta su capacidad de comprensión, sino sobre lo que ni siquiera se atreve nadie a pensar, y menos a investigar o a escribir, para evitarse enojosas fricciones. De este modo la zona prohibida se extiende en proporciones que no estuvieron jamás en la mente de quien trazó sus primeros límites, y la acción inhibidora crece en la medida en que se teme su proximidad.

9. Karl Vossier, Introdtceión a la literaturs espoñola del siglo do Oro. Trad. de F. González Vtcén, Buenos Aires, Austral, 1945, pág. 75.

10. Apud K. Vossler, loe. rit. 
Circunscrito, pues, real o imaginativamente, el horizonte mental de los españoles del siglo XVII, encerado entre temerosas fronteras, el genio hubo de ceder al ingenio. Y las diferencias entre ambos talentos son profundas. Una importantísima nos interesa ahora. Es ésta: mientras el genio utiliza los datos como simples datos, el ingenio los convierte en problema. Si el genio utiliza dos hechos para descubrir otro nuevo, el cual a su vez, usado como dato servirá para aliarse a otro en zigzagueante proceso de avance, el ingenio, por el contrario, utiliza dos hechos, no para inferir o deducir con ellos, sino simplemente para combinarlos. Ingenioso es el hombre que combina; genio el que inventa. $\mathrm{Y}$ el movimiento que describe la mente ingeniosa es circular, cerrado sobre sí mismo. Con unos datos que no pueden alterarse, el único juego posible es problematizarlos, esto es, disponerlos ingeniosamente, para que, si no otra novedad, ofrezcan por lo menos la de una inusitada combinación. Todo el arte barroco, salvo contadísimos casos, con su pluralidad de estilos, no es otra cosa que una magna combinatoria. $Y$ cuando la fuerza creadora decrece y se remonta la segunda mitad del siglo, asistimos al penoso espectáculo de ver cómo aquel movimiento concéntrico, en lugar de seguir creciendo, poderoso y avasallador, vencido el ímpetu que le hacía ensancharse, se va recluyendo y circunscribiendo hasta hacerse ínfimo. Aquel cerrado pero intrépido paraíso del arte se convierte paulatinamente en jardincillo de paradojas, turbio espejo de vanidades y charco de ranas.

La religación de Cielo y tierra que definimos como postulado determinante del siglo barroco, confiere a éste unos caracteres singularmente cercanos a los de la Edad Media. Se han señalado algunos evidentísimos. 
En política, por ejemplo, el XVII y el XV presentan en común el gobierno del rey a través de validos; las danzas de la muerte tienen su correspondencia en los autos sacramentales; las semejanzas entre Gótico y Barroco han merecido la atención de abundantes historiadores como Wölffling, Woeringer, Schaeffer, Woermann y Spengler; el lenguaje poético ofrece curiosas y a veces turbadoras proximidades en ambos siglos ${ }^{(x)}$; la literatura presenta en los dos un apogeo del romance ${ }^{(x)} \ldots$ Inútil sería continuar trazando semejanzas que, por otra parte, nos llevarían muy lejos.

Desde el punto de vista de las circunstancias, ya hemos tenido ocasión de señalar cómo los límites de lo natural y lo sobrenatural, a fuerza de acercarse en el corazón de los hombres, tienden a su confusión, a su dilución, dando lugar, por un lado, a tipos humanos aberrantes en cuanto a su comportamiento moral, y de otro, a la proliferación de las supersticiones, esto es, a la sistemática abdicación de lo racional ante la fuerza sugestiva de lo misterioso. El país entero se pobló de endemoniados, posesos, milagrados, llagados, beatas, que las más de las veces, tras haber sido ampliamente admirados por las gentes ingenuamente devotas, iban a dar con sus huesos en las cárceles de la Inquisición. Así

11. Y no sólo el XVII las presenta con relación al slglo XV sino con épocas mås pretétitas, con la literatura medieval en lengua latina, Incluso. E. R. Curtius, por ejemplo, tras haber señalado concomitancias entre Gongora y Calderon, de un lado, y Abelardo, Alaln de Lille, G. de Chatillon, Walter Map, Pedro Riga y Juan de Garlandia, de otro, escribe: .St los españoles del siglo XVIl emplean dos metaforas tan artificlosas y rebuscadas como hidropesio y eftora de plama y sI los poetas latinos del siglo XIl hacen otro tanto, este solo hecho basta para demostrar los vínculos que unen al batroco español con la teoría y la práctica de la literatura latina medieval. . Literatura europea y Edad Medin latino, trad. de Margit Feenle Alatorre y Antonio Alatorre, Mejico, Fondo de Caltura económica, 1955, pág. 395.397. Curtius no se pronuncia acerca de la naturaleza de esos vínculos, que blen pueden explicarse por la forzada limitacion de la mecánica combinatoria. Vid., Igualmente, Robert Ricard, sWits et cogudezas, ‘Revue du moyen áge latin, , IV, 1948, 2835.

12. Cfr. sobre todas egtas homologias, E. Frutos. La flosofie de Calderón en sus autas asera mentalea. Zaragoza, Institución Fernando el Cat6́lico, 1952, págs. 32 y ss. 
ocurrió con la célebre hermana Lorenza, que durante diez y seis años atrajo peregrinos a Simancas, en donde vivía, para contemplar sus arrobos místicos, y que hubo de ser prendida al descubrirse su amancebamiento con dos "beatos ermitaños" y hasta quizá con el donado de un convento ${ }^{\left({ }^{3}\right)}$. Las llagas "milagrosas" se extendieron con una fecundidad que causa pasmo: "Cunde tanto esto de las llagas - escribía el P. Juan Chacón, en I6 34 -que no se tiene ya por sierva de Dios la.que no tiene las cinco llagas». La visionaria Lorenza de Murga hubo de ser supliciada para que confesara sus deshonestidades y embelecos. Más escandaloso fué el caso de la endemoniada fingida de Valladolid, la cual, según comenta con asombro el buen Chacón, consiguió llevar adelante su engaño en lugar tan "populoso, y donde se encierra lo más ilustre y político, y los más aventajados ingenios, acompañados con toda la variedad de ciencias que en las academias de España se profesan. Pero así andaban entonces esas ciencias, a merced de cualquiera bellaca que urdiera con ingenio una aventura con el más allá. Las brujas gozaban derecho de libre tránsito y hasta las gentes de Religión ofrecían campo libre para sus travesuras. Un hermano jesuita, en Alcalá, se vió visitado por una, con aspecto de moza garrida, contra la que se defendió como pudo. Cuando los vecinos entraron en su aposento lo hallaron desnudo, tendido en el suelo, yerto y $\sin$ pulso ${ }^{\left(x_{4}\right)}$. Todos estos acontecimientos hormiguean a lo largo del siglo XVII, con una densidad tal que produce pasmo. Hoy divierten tanto como

13. V/d. Relatas diversos de vartas de jesuitas (1634-1648), seleccín de J.M." de Cossio. Buenos Alres, Austral, 1953, pags. 18-20.

14. Puede verse la relactón de estos y otros varlos sucesos en el libro cltado en la nota anterior, y muchos más en la colección epjatolar de que esta selección procede, publicada por Gayangos en el Memárial Historico Eapañol, a partir de 1861. 
apenan, porque configuran todo un siglo de nuestra cultura con tintes bochornosos. Pensemos, por ejemplo, que el poeta más editado en el seiscientos no fué Lope, ni Góngora, ni Quevedo, sino un oscuro y ripioso coplero, Alonso de Ledesma, de cuya calidad y familiaridad con los asuntos del Cielo dan idea estos versos, con los que cantaba, por ejemplo, las obras de virtud:

Si por lo que el mundo diga, obras de virtud hacéis, haced vos lo que debéis, y dad al mundo una higa. Vestid al pobre por Dios, que si lo venís a dar por vuestro particular, una higa para vos ${ }^{(x s)}$.

Si recapitulamos cuanto llevamos dicho para utilizarlo como medio de encontrar una clave interpretativa de Feijóo, obtendremos estos resultados:

r. El genio creador ha dejado paso, durante el siglo XVII, al ingenio combinador. Cuando éste deja de hacerse productivo, el arte, como las restantes manifestaciones de la cultura, deja paso al artificio, e incluso a un mero artificio del artificio. La vida cultural de la patria se hace improductiva.

2. Una violenta e impensada consecuencia de la prudente religación de Gracia y Naturaleza operada en Trento, conduce, en el terreno de las creencias, a una perturbadora implicación de una en otra; manifestaciones peculiares de este vicioso extremo son las herejías de los alumbrados, por un lado, y la proliferación de

15. Bomangere y canclocero sagrados, Bibli. Aut. Eap., 1885, pag. 153. 
supersticiones y milagrerías con que se enmascara la observación reflexiva de los hechos. El espíritu razonador deja paso al espíritu mágico, que se instala incluso en la cámara del propio hechizado rey D. Carlos.

El año 1676 , en la plenitud de tanta desventura, cuando las vidas de los últimos grandes artistas barrocos se están extinguiendo, comienza la de Benito Jerónimo Feijóo y Montenegro. La cultura española durante la mocedad y primera varonía del benedictino, había de atravesar un vértigo de descenso, $\sin$ igual en toda nuestra historia. Es difícil imaginar unos años más trágicamente desoladores que este último cuarto del seiscientos y el primero del setecientos. Por eso resulta pasmoso este auténtico milagro que fué el P. Feijóo. Cuando Luzán, Sarmiento, Torres, Mayáns, Flórez o Isla, esta primera promoción de prohombres dieciochescos, tienen ocasión de asomarse a la vida del país, el panorama se ofrecía ligeramente favorable, sino totalmente cambiado. Pero Feijóo, bastante mayor que todos ellos, había tenido que realizar un hercúleo esfuerzo en plenas tinieblas, y además, esto es lo portentoso, iba a llegar más lejos que ninguno, dueño como era de una superior capacidad de interés y de una razón más lúcida. Quien se acerque a su Teatro Crítico o a sus Cartas eruditas $\sin$ más objeto de consideración que las obras mismas, tendrá mucho que admirar; quien además se tome el trabajo de leer a muchos de sus contradictores, o simplemente, cualquier otro libro contemporáneo, tendrá motivos más que sobrados para el pasmo.

Efectivamente, los veinticinco primeros años del siglo XVIII constituyen, culturalmente, una lenta putrefacción de los residuos barrocos. Los caracteres enunciados como definidores del espíritu sescentista, se abultan ahora grotescamente. Todavía en 1737 , el P. Lozano 
puede escribir estas palabras escalofriantes: "Nadie ignora el defecto que entre nosotros se halla, en cuanto a la latinidad. Lo cual confirma haberme dicho persona muy fideligna y condecorada, a quien toca saberlo, que son muchos los que se van a examinar para confesores, que no entienden el Prontuario de Larraga; y si sucede esto estando en romance, más se pudiera temer estando en latín». ${ }^{(x)}$ Esta acusación gravísima, y nos resistimos a creer que justa, lanzada contra el clero por el P. Lozano, fué combatida luego en el Diario de los Literatos. ${ }^{(x 7)}$; poco importa ahora su discutible exactitud; importa sólo el hecho de que pudiera ser formulada. El P. San Agustín, autor de una Grammática impresa a principios de siglo, puesto a lucubrar sobre el origen de nuestro idioma, disparata así: "Siendo Túbal el que vino a poblar nuestra España con su familia, el ángel tutelar de ella es de creer... le enseñaría nuestra lengua española-castellana, la que se infiere ser antiquísima y no derivada de la latina, como algunos han juzgadon ${ }^{\left({ }^{(8)}\right)}$. iEsto se escribía a más de dos siglos de distancia de Nebrija y a uno de Alderete y Covarrubias! Y hemos de suponer que, en la Grammática del P. San Agustín, aprendieron su latinidad y fijaron sus opiniones lingůísticas muchos centenares de estudiantes españoles contemporáneos de Feijóo. En cuanto al estilo, la lengua había llegado a una estremecedora situación. Un botón de muestra: he aquí cómo titulaba su principal obra el franciscano Soto Marne, famoso por su feijóofobia: Florilegio sacro que en el celestial ameno frondoso Parnaso de la Iglesia riega /místicas

16. P. Marcos Lozano. Adieciesario al Promptzarto de Theologita Moral del Remo. P. M. Fr. Franeleco Lerrate. Madrid, 1737, prologo.

17. T. I., art. XV, págs. $255-6$.

18. Ct. F. Lazaro, Las ideas liagöisticas en España darante ol aigito XVIII, Madrid, CSIC, 1949, págı. 92-93. 
flores) la Aganipe Sagrada, fuente de Gracia y Gloria de Cristo. Divididos en discursos panegíricos, anagógicos, tropológicos y alegóricos, fundamentados en la Sagrada Escritura. La extravagancia de este título-uno entre la muchedumbre que podríamos aducir-se potenciaba aún en el texto. Otra muestra del mismo Soto: ${ } \mathrm{Me}$ resolví a tomar la pluma para resistir la fuerza con la fuerza, disipando a fogosas radiaciones de la verdad las densas nubes que, compactadas a vaporosas preocupaciones del engaño, vaguean sosteniḍas del más injustificable empeñon. ${ }^{(x)}$

En medio de estas densas nubes le fué preciso moverse a Feijóo. Y lo hizo por el único camino posible: horadando aquella gelatinosa capa de ignorancia para asomarse a la realidad europea, y regresando después, con el espíritu fortalecido por las luces, a este entrañable campo de batalla que era su patria. Pero esta afirmación-que fué acusación entre muchos de sus contemporáneos-necesita ser matizada, si no queremos que la personalidad de Feijóo, y su lección, se nos escapen por demasiada simplicidad.

Lo que Fr. Benito halló por el horizonte europeo fué una conciencia en crisis, cuyos caracteres ha descrito Paul Hazard, en uno de los libros más hermosos de la historiografía contemporánea. No podemos contraer a los límites de esta exposición todas las peripecias de la trascendental aventura del pensamiento de Europa que alli se describe. Nos contentaremos con una definición clave: lo que Feijóo encuentra en su excursión por la cultura ultramontana es un descrédito absoluto del principio de autoridad. Dicho en otros términos, lo que atrae

19. Cfr. Feljoo, Justor repalea de mingas acasaciones (1749). Cito por la 3.a Impresibn, Madrid, 1757, pág, 13-20. 
a los sabios no es la preocupación por las causas primeras, sino por las segundas causas. Triunfa un método, no una filosofía. Un método, por lo demás, nacido en una filosofía concreta, en la de Renato Descartes, pero que interesa por sí solo más que los presupuestos en que se basa. Así lo confesaba, en I688, el francés Fontenelle, en su Digressión sur les Anciens et sur les Modernes: *Antes de Descartes-escribe-se razonaba más cómodamente. Es él, me parece, quien ha traído este nuevo método de razonar, mucho más estimable que su filosofía misman. ${ }^{\left({ }^{\circ}\right)}$ Ese nuevo método es un arma nueva puesta en manos de los hombres, y radica en una entera confianza en la razón y en una fe absoluta en el progreso. El arquetipo humano no es ya, concretamente en Francia, el bonnete-bomme, para el que Faret exigía, cincuenta años antes, en plena edad clásica, una "mediocre teinture" en las más agradables cuestiones de que se habla alguna vez en las reuniones mundanas ${ }^{\left({ }^{(x)}\right.}$. Por el contrario, el hombre culto moderno, al filo del setecientos, es un filósofo, el cual, según se definirá años más tarde en la Enciclopedia, "no admite nada sin prue$\mathrm{ba}, \mathrm{ni}$ asiente a nociones engañosas, [y] plantea exactamente los límites de lo cierto, de lo probable y de lo dudoson.

La razón, que implica la observación, la justificación, la comprobación rigurosa, se está aplicando con urgencia a todos los frentes de la cultura, y nada, ni las instituciones, ni las creencias ni la historia escapan a su filo agudo. El saber se caracteriza ahora por dos notas fundamentales: experimentación y enciclopedismo. Un sociólogo y pensador político, como Montesquieu,

20. Apud H. Bénac, Le tiessieiende, Paris, Hachette, 1949, pág. 113.

21. Ihid., pig. 31. 
para comprobar la hipótesis de que los climas influyen en el temperamento de los hombres, hasta el punto de que, en los climas fríos, la exigencia de placeres es menor, se arma de un microscopio, toma una lengua de cordero y examina las diferentes dimensiones que poseen las terminaciones nerviosas, según la lengua esté caliente o helada. Con esto, aquella ley sociológica piensa Montesquieu, pasa del estado de hipótesis al de tesis incontrovertible ${ }^{(2 a)}$.

El enciclopedismo; en estos años en 'que Feijóo libra su batalla, está representado por dos cáusticos escritores franceses, cuyo influjo europeo fué colosal: Pierre Bayle y Bernard Fontenelle. Ambos se encuentran abundantemente citados por el Padre Maestro, aunque éste difiriera abismalmente de su espíritu. Porque los dos son las puertas por las que el racionalismo a ultranza, postulado en los albores del siglo XVIII, llegará a sus últimas consecuencias en materia de fe. Efectivamente, no es el dogmatismo científico, político o social el único dominio que se somete a la investigación racional: son los mismos dogmas. Más o menos larvada, en los escritos de Bayle o Fontenelle, hay una ironía cuando no una decidida actitud de ataque frente a la religión.

Fr. Benito Feijóo trasplanta a su patria el sistema enciclopédico que, con tanto éxito, se está aplicando en Europa: Y, con él, su método, la experimentación, la crítica. Si la palabra ingenio podía ser la clave de nuestra cultura barroca, el vocablo crítica resume en cifra la nueva cultura a la que Feijóo sirve, la cultura de las luces. Si el ingenio, decíamos, es un método de combinación, la crítica es un método de descubrimiento; si con el ingenio se establece un movimiento rotatorio,

22. Cfr. L' esprit des leis, libro XVIII. 
mediante la crítica se obtiene un impulso de avance. La crítica del XVII, la del Criticón graciano, por ejemplo, se ejercita en un orden moral; la del XVIII, en un orden natural. Llevando esta palabra al título de su obra enciclopédica, Feijóo se instalaba, mediante un intrépido salto, en plena modernidad, y daba al enmarañado curso de nuestra cultura, delirante casi a fuerza de girar en torno de sí mismo, una salida, un cauce, una recuperación de su ya olvidado orden de progreso.

Sin embargo Feijóo no compone un diccionario enciclopédico, al modo de Bayle. Y al interpretar este hecho tocamos ya uno de los rasgos diferenciales de nuestro monje. Efectivamente, el diccionario al estilo del de Bayle o al de la Encyclopédie, implica una intención que le sirve de sustrato. Fijémonos en el designio de esta última. Según D' Alembert ha sido propósito de sus redactores aexponer el orden y encadenamiento de los conocimientos humanos». Ello implica una metafísica, atea en este caso concreto. El orden alfabético del famoso diccionario era, en gran medida, un ardid para desempeñar sin escándalo sus ocultos propósitos. De todos es sabido cómo se apeló al sistema de referencias para atacar los dogmas cristianos y sus principios morales. Los artículos atingentes a estas cuestiones fueron confiados a renombrados teólogos y sometidos a la aprobación eclesiástica. De este modo, la doetrina resultaba irreprochable, para quien se atuviera exclusivamente al contenido de aquel artículo. Pero he aquí que al final de éste, se remite a otro, en el que so ingenua capa, se deslizan doctrinas claramente adversas al primero. Un nuevo reenvío, conduce ahora a un tercer artículo; y de éste a un cuarto, y así sucesivamente. Al llegar el lector al punto final de su recorrido, nada 
queda ya de lo dicho en el artículo base; si antes se le ofreció en calidad de cebo el haz de una doctrina, ahora posee exactamente el envés, como conclusión.

Fr. Benito no sale a la palestra con propósitos que no sean, a la vez, una disipación de errores y una defensa cerrada de la religión. Por eso las cuestiones por él examinadas no siguen más orden que el puro azar o la mera ocurrencia. En este sentido podemos afirmar que Feijóo posee una mente enciclopédica, pero no enciclopedista. ${ }^{\left({ }^{3}\right)}$ Entre una y otra, entre lo enciclopédico y el enciclopedismo media un abismo cuyo salto jamás tentó a este piadoso varón que alguna pluma necia ha llamado el Voltaire español.

El cristianismo íntegro del P. Feijóo es su rasgo diferencial más profundo frente a los escritores filósofos de allende los Pirineos. Vamos a considerarlo, en atención a su gran importancia, refiriéndolo a dos órdenes de cuestiones: la refutación de falsos milagros y el establecimiento de bases estrictamente naturales para la moral. Conocido es el ardor con que el Padre Maestro se aplicó a un meticuloso deslinde entre los órdenes natural y sobrenatural, entre la religión y la magia. Era, por tanto, una empresa de preclara naturaleza cristiana. Pues bien, los "filósofos" franceses aprovecharon la denuncia de claras falacias, de supersticiones y errores, para conducir la duda a todo el edificio religioso. En Voltaire el hecho resalta con tanta claridad, que no merece comentario. Para comprobar la radical oposición entre Feijóo y este nuevo espíritu, vamos a comparar las actitudes respectivas de Fr. Benito y de Bernard Fontenelle ante dos falsos milagros. Cuenta este último ${ }^{(24)}$ la prodigiosa

23. Cfr. S. Montero Diaz, Galieis en el P. Feijó, Madrid, 1929, aducido por G. Maration, op. eit. pág. 46.

24. L' hlatoire des oraeles, 1686, primeca disertación, IV. Puede leerse el texto aludido en la antologia de Lagarde Michard, Les grands auteurs francela, IV, Parts, Bordas, 1953, págs. 24-25. 
historia de un diente de oro, que en I 593 se dijo haber salido a un niño silesiano de siete años. Horstius, profesor de Medicina de la Universidad de Helmstad, aseguró que el diente había sido concedido a este niño por Dios para consolar a los cristianos afligidos por los turcos. «Imaginaos - comenta Fontenelle con sospechosa ironía - qué consuelo y qué relación entre aquel diente de oro y los cristianos y los turcos!». Aduce, a continuación, nombres de otros, cómicamente latinizados, que escribieron con pormenor acerca de este prodigio. Pero he aquí que, un buen día, se le ocurrió a un orfebre examinar la prodigiosa pieza y halló que era sólo un vulgar diente al que con suma destreza se había pegado una hojita de oro.

Tras los hechos, Fontenelle formula la consecuencia: se debió comenzar por el examen del diente, antes de escribir los libros. Y añade: "Nada hay más natural que hacer lo mismo en toda clase de materias. No me convencen tanto de nuestra ignorancia las cosas que existen y cuya razón no conocemos, cuanto aquellas que no existen para las cuales encontramos una razón». Y concluye, de modo más claro y más trascendente aún: "Quiere esto decir que no sólo no poseemos los principios que conducen a lo verdadero, sino que tenemos otros que se acomodan muy bien con lo falso". La intención de Fontenelle queda nítida; ha dejado prendida en la Religión su aguijoncillo, y ya puede ponerse medianamente a cubierto, líneas más abajo, con estas palabras: "Cuando se escribe de religión, sobre todo, es bastante difícil que, según el partido que se adopte, no se dé a una falsa religión ventajas que no le son debidas o que no se dé a la verdadera falsas ventajas que no necesitan. ¿Pero es que, nos podemos preguntar, cree acaso Fontenelle que hay una religión verdadera? 
Veamos ahora cómo se enfrenta Fr. Benito Feijóo con otro falso milagro. Ocurrió el hecho en Agreda. Una vieja, criada de un sacerdote, creyó muy provechoso para su bolsillo esparcir la idea por la villa de que un crucifijo que había en la casa de su amo sudaba sangre. Acudían las gentes piadosas a ver la imagen, y pudieron observar en reiteradas ocasiones cómo el rostro del Crucificado estaba tinto en sangre. "Fué notable la conmoción de todos, nobles y plebeyos; hubo rogativas, procesiones, votos, limosnas», puntualiza Feijóo. Pero había un escribano, que no se rendía al prodigio; se quedó oculto una noche en la habitación del crucifijo "y allí vió cómo la vieja, después de recogido el amo, iba al sitio, y sacándose sangre de las narices, teñía con ella, según la porción que le parecía, el rostro de la imagen. Hecha información jurídica sobre el caso, el Corregidor ordenó que se dieran doscientos azotes a la vieja, de los cuales asegura Fr. Benito "que fueron tan bien merecidos como cuantos hasta ahora se dieron en las calles públicasn. ${ }^{(25)}$. Como conclusión de otro falso milagro fraguado por "un hereje holandés», vuelve el buen benedictino a mostrar su conformidad con la sanción: "Fué castigado severamente-asegura-; y de este modo, sirvió para confusión de los herejes el mismo suceso que, a no haber sido examinado, diera materia al rubor de los católicosw. ${ }^{(06)}$

En estas rúbricas de ingenuo asentimiento con los rigores de la justicia se concreta la diferencia entre un "filósofo» como Fontenelle y un cristiano como Feijóo. Inútil resultaría extenderse en este intuitivo cotejo. Contrastemos sólo las sibilinas insinuaciones del normando,

\footnotetext{
25. TC, III, disc. VI, 13.

26. Ihid., 14.
} 
con esta categórica afirmación del gallego: "No esperemos a que la enemiga de los herejes descubra lo que erró la falsa piedad de algunos católicos. Seamos nosotros los delatores de la impostura antes que nuestros contrarios nos den con ella en los ojos, haciendo guerra a nuestras verdades con nuestras ficciones " ${ }^{(27)}$.

Feijóo no sobrepasa, pues, los límites del experimentador, que guarda bien a salvo su fe. Si tuvo que quitar adherencias sobrepuestas a la religión como una flora parásita, lo hizo siempre con tal pulcritud que ni rozó la piel de sus convicciones.

Otra cuestión que, según hemos adelantado, preocupaba grandemente a los "filósofos" ultramontanos era la posibilidad de que la moral no necesitara del cristianismo como sustento. En efecto, desde fines del siglo XVIII, una serie de viajeros europeos han llegado hasta la misteriosa Turquía, la lejanísima China, la sugestiva Persia, y, a su regreso, publican libros leídos con avidez. Hay además las Lettres édifiantes et curioses de los jesuítas misioneros en Extremo Oriente. Todos estos relatos, en manos de los "modernos" son materia apta para someter a examen mil y mil cuestiones de la moral católica; se exaltan las virtudes y la felicidad de los salvajes de tierras exóticas, vigorosos, simples, prudentes y felices porque se someten íntegramente a lo que de ellos demanda la madre Naturaleza. De este modo, los pintorescos atractivos de la moral natural van socavando el intacto prestigio de la moral cristiana.

Feijóo, lector empedernido de los sugestivos relatos de misioneros y exploradores, supo también sustraerse a las consecuencias transcendentales que por París o por Londres se sacaban a estos edificantes relatos. Veámos-

27. IbId., 15. 
lo con una muestra que es además un notable ejemplo de su estilo literario: "Mahomet Alibeg, mayordomo mayor del rey de Persia, al principio del siglo pasado, subió a tan elevado puesto desde el humilde estado de pobre pastorcillo. Un día que aquel rey andaba a caza, le encontró tañendo la flauta y guardando cabras en el monte. Por diversión le hizo algunas preguntas, y prendado de la vivacidad y agudeza con que respondió el niño se le llevó consigo a Palacio... de modo que, elevándole prontamente de cargo en cargo, vino a colocarle en el que ya dijimos, de mayordomo mayor. Su integridad inflexible al atractivo de los presentes (cosa muy rara entre los mahometanos) concitaron contra él poderosos enemigos, pero sin atreverse a intentar hostilidad alguna, por verle tan dueño del ánimo del soberano. Hasta que, muerto éste y entrado el sucesor que era joven, le sugirieron que Mahomet había usurpado al erario real grandes tesoros. Ordenóle el príncipe que, dentro de quince días, diese cuentas, a que Mahomet, intrépido, respondió que no era menester esa dilación, y que si su majestad fuese servido de ir inmediatamente con él a casa del tesorero, allí se las daría. Fué el rey, seguido de los acusadores; pero se halló todo en tan bello orden, y con tanta exactitud ajustada la cuenta de los caudales en los libros, que nadie tuvo qué decir. De allí se pasó a la casa del mismo Mahomet, donde el rey admiró la moderación que había en alhajas $\mathrm{y}$ adornos. Pero observando uno de los enemigos la puerta de un cuarto cerrada y guarnecida con tres cadenas fuertes, se lo advirtió al rey, el cual le preguntó qué tenía cerrado en aquel cuarto. «Señor-respondió Mahometaquí guardo lo que es mío. Todo lo que hasta ahora se ha visto es de vuestra majestad „. Diciendo esto, abrió la puerta. Entró el rey en el cuarto, y volviendo a todas 
partes los ojos, no vió otra cosa sino las alhajas siguientes, pendiente cada una de un clavo en las paredes: una zamarra, una alforja, un cayado pastoril y una flauta. Atónito las miraba el rey, cuando poniéndose de rodillas delante de él, Mahomet le dijo: «Señor, éste es el hábito y éstos los bienes que yo tenía cuando el padre de vuestra majestad me trajo a la corte. Esto es lo que entonces tenía y esto lo que ahora tengo. Sólo esto conozco por mío. Y pues lo es, suplico con el mayor rendimiento a vuestra majestad me permita gozarlo, volviéndome al monte de donde me trajo mi fortuna”. Aquí, no pudiendo contener el rey las lágrimas, le echó los brazos al generoso valido, y no contento con esta demostración, despojándose prontamente de sus reales hábitos, se los hizo vestir a Mahomet, lo que en Persia se estima por la suprema honra que el rey puede hacer a un vasallo. De este suceso resultó que Mahomet logró después constantes la confianza y cariño del príncipe toda su vida. ${ }^{(28)}$

Hasta aquí la anécdota lisamente contada por Feijóo; un "filósofo" a la moda hubiera tenido excelente ocasión para precipitarse por la pendiente de las consecuencias: el sarraceno Mahomet Alibeg, por simple moral natural, era un modelo para validos y ministros cristianos, atentos tantas veces a su medro personal y al delictivo acopio de fortuna; ¿no era por tanto preferible la moral del honrado Mahomet a la de los deshonestos ministros católicos? Feijóo, como en el caso de los falsos milagros antes descrito, se limita a poner una rúbrica ingenua, bienintencionada, de quien sabe que el nombre de cristiano, sin más, no preserva del crimen. $Y$ así apostilla la edificante historia de Mahomet: "QQué lástima

28. TC, I. disc. 1V, 21 . 
que este desinterés, esta elevación de ánimo, esta rectitud, esta moderación, estuviesen depositadas en infiel!n.

Hagamos alto para mirar atrás, antes de reemprender la última y breve jornada de nuestra marcha. Hemos dibujado someramente el penoso ambiente en que tiene que desarrollarse la existencia del Padre Feijóo; lo hemos visto estirarse como un árbol que huye de la calígine y puja por recibir aire limpio y luz del sol, asomándose a Europa. Y sabemos ya que en lugar de aire ha hallado lo que los españoles de entonces llamaban «el ventarrón del Norte", y en vez de luz, ha encontrado las luces. Pero ni un instante aquel vigoroso tronco se ha torcido ni se ha deslumbrado: al enciclopedismo ha respondido con su espíritu enciclopédico; a la implicación de lo religioso y lo mágico, que sirvió a los iluminados setecentistas para confundir ambos dominios en una misma condena, Feijóo opone un nítido deslinde entre superstición y fe; por último, al enfrentamiento entre moral natural y moral cristiana, él opone una identificación y una coincidencia: si Mahomet obró correctamente y un ministro cristiano lo hace con dolo, la diferencia estriba en que Mahomet se ha comportado como debiera hacerlo un cristiano y el mal ministro como lo suelen hacer los infieles. Para ello Fr. Benito, se ha cuidado de decirnos que los mahometanos son singularmente flexibles al atractivo de los regalos. El valido era, pues, una excepción. El pensamiento de Feijóo no va más lejos en sus inferencias.

En estos puntos, apresuradamente descritos, se asienta la personalidad del benedictino frente a la niveladora cultura europea. Veamos ahora cómo la afirmó en la penumbrosa situación de su patria.

$\mathrm{El}$ arma que el buen monje esgrimía en su mano resultaba aquí nueva, inusitada; era la razón, la simple 
razón natural apoyada en la experiencia. A la niebla espesa de escritos atiborrados de argumentos de autoridad, escritos con los ojos cerrados y solo el oído abierto, Feijóo viene a poner, en nítida prosa, ni más ni menos que lo que él ha observado o su buen sentido le dicta. Sus ensayos se ven frecuentados por aserciones como ésta: "El fundamento grande de mi sentir es la experiencia" ${ }^{(29)}$. He aquí su honda revolución. Nada, ni el testimonio de un antiguo o de un moderno escapa a su personal comprobación, si ello es posible, o al examen de su recto juicio.

Y luego, con ésta, otra profunda novedad: el deslinde riguroso, exigido a la vez por su conciencia de cristriano y su fervor de sabio, entre la naturaleza y la sobrenaturaleza. Recordemos hasta qué punto se habían confundido desde Trento, de qué manera el curso del Humanismo renacentista se había alterado en nuestra patria, para dar lugar a una nueva cultura, a una nueva y gloriosa Edad Media. Y cómo, andando los años, la gloria había dejado ancho campo a la miseria. Pues bien, el esfuerzo de Fr. Benito Feijóo, ino es el de un nuevo humanista, el de un sabio al igual que aquellos del amanecer del quinientos, y como ellos comprometido en aislar para su amoroso estudio los misterios del mundo terrenal? De esta manera, el benedictino viene a instalarse en el polo opuesto de la conciencia barroca. He aquí el inicial significado que atribuímos a Feijóo en la historia cultural de España. Pero esto resulta aún escaso para una caracterización. Se hace preciso que, con paso acelerado, recorramos algunos lugares de su batalla, para contemplar además el gesto con que la libró.

La primera nota de ese gesto es el brío. Un brío

29. TC, I, disc. VII, 3. 
violento como correspondía a lo profundo de sus convicciones y a la urgencia de su tarea. Cuando un contradictor de cierta entidad como Salvador José Mañer opuso sus opiniones disconformes con algunas del Teatro Crítico, ciertamente con respeto, Feijóo alzó su voz descompuesta, llamándole "pobre Zoilo, que nunca había hecho otra cosa que morder escritos ajenos " ${ }^{(30)}$. O cuando el P. Soto Marne, con su pintoresco conceptismo, saltó a la palestra en contra suya, Feijóo refutó aquel estilo en el siguiente tono: "De este modo, lo que logró (Soto) fué hacer un estilo que da asco, lleno de verrugas, costras, diviesos, torumbones y cobanillas... Sin embargo, todo esto es bueno para payos y tontos, que tienen por gala de la pluma esta suciedad del idioma. Pero si Dios no le dió habilidad para más, ¿qué pudo hacer el pobre sino suplir la elegancia que le falta con la extravagancia que le sobra? ${ }^{(3 x)}$.

Este brío tuvo a veces que ceder ante la densidad de las opiniones que pretendía horadar. Lo vemos así, por ejemplo, criticando con todo rigor el pretendido milagro de la campana de Velilla, pero cubriéndose con reservas porque ciertas autoridades eclesiásticas no estaban persuadidas de su falsedad ${ }^{(33)}$; o bien, atacando violentamente a las personas que se deleitan con el suplicio de los animales, pero ante el temor de hacerse impopular si alguien veía en ello una impugnación de las corridas de toros, apostillando: "Debe confesarse que hay mucha distancia del vicio de mortificar un bruto por algún deleite que de ello puede resultar accidentalmente, a la sevicia de deleitarse en el mismo tormento

\footnotetext{
30. Apud Millares, op. vit., pág. 34.

31. Justa repulsa, loc. cit.

32. Cfr. TC, disc, IX, 82-142.
} 
del bruto". ${ }^{(33)}$ Son, como vemos, pequeñas fintas protectoras, de las que hasta las personas mejor intencionadas, como Feijóo, se ven obligadas a usar con excesiva frecuencia. Pero su brío, su valentía no sufre por ello desdoro. En una carta exhumada por el Dr. Marañón, lo vemos aludir donosamente al Inquisidor general reinante, «amantísimo de la antigualla, que está amenazando con el rayo en la mano a todo libro que dice algo de lo infinito que se ignora en España " ${ }^{(34)}$.

Junto al brío, Feijóo hace alarde - y es ésta otra nota diferencial que importa resaltar - de una absoluta independencia de juicio. Como decíamos, ni los antiguos ni los modernos, por serlo, merecen su asentimiento. De ahí que resulte materialmente imposible clasificarlo en una dirección filosófica o científica, porque de todas aprendió y a todas combatió. No sigue ni a Aristóteles ni a Descartes, a Leibniz ni a Gassendi. Aduce unas veces a Fontenelle, Malebranche, Newton o cita con reverencia el Diccionario de Trévoux, pero otras argumenta contra ellos o pone reservas a sus afirmaciones. Quizá no haya en toda su obra más que una constante devoción: la que sentía por el Canciller Bacon; el gran promotor de la ciencia experimental. Cuando Fr. Benito fué acusado por su afecto a este filósofo protestante, se defendió con gallardía: "Sí, reverendísimos' míosdecía con ironía a los religiosos que lo atacaron-, he hablado siempre con aprecio de este autor hereje y le elogiaré siempre que se ofrezca, pero conteniéndome siempre, como hasta ahora lo hice, dentro de los límites permitidos" ${ }^{(35)}$.

Esa independencia libró a Fr. Benito de dos extre-

33. CE, III, c. 27.

34. G. Marahon, op. ett., pg. 39 .

35. CE, II, c. 13 . 
mos igualmente necios: uno, el discipulado ancilar que tanto tiene de esclavitud, y otro la apresurada adopción de todo lo novedoso. Hay que leer con qué visible desprecio se revolvió contra el tristísimo, el aburridísimo. Gabriel Alvarez de Toledo-tan admirado por Torres Villarroel-el cual, dice Feijóo, «quiso exornar la Sagrada Historia del Génesis con las nuevas opiniones filosóficas, aliños tan forasteros a aquel asunto como el de su impropio y afectado estilo ${ }^{\left({ }^{(36)} \text {. }\right.}$

Brío e independencia se alían, como en todo pensador digno de tal nombre, a la tolerancia o, si ésta no es posible, al respeto. Hay un discurso, admirable entre todos los suyos, titulado Guerras filosóficas ${ }^{(97)}$, en el que este espíritu de tolerancia queda bellamente ejemplificado. He aquí un significativo punto para la comprobación: "Cuando tronó con más fuerza la cólera de los aristotélicos fué al verse atacados de cartesianos, gasendistas y maignanistas. Sobre Descartes, así como halló más sectarios su sistema, cayó también la mayor parte del nublado. Son innumerables los escritos donde se ve tratado de loco, temerario, delirante, hereje $\mathrm{y}$ aun ateísta. Ni faltó para Gasendo y Maignan su pedazo de tempestad... Yo estoy bien hallado con las formas aristotélicas y a ninguno de los que las impugnan sigo. Pero tratar de rudos a Descartes, Gasendo y Maignan es hacerles una gravísima injusticia... No niego que algunos de los que pasan por sabios en el mundo, por falta de reflexión creen, como si fuera de fe, la doctrina de su escuela: genios superficiales, hombres de mucha frente y poco fondo, láminas en quienes se estamparon como mecánicamente las letras y es imposible borrar la impresión,

36. TC, I, disc. XII, 40.
37. TC. I, disc. I. 
porque lo resiste la dureza de la materia. Estos siguen su partido con buena fe, aunque tal vez sea defectuosa la caridad... Adonde se descubre más esta maliciosa política es en la acusación que recíprocamente se hacen los filósofos de ser sus doctrinas incompatibles con los sagrados dogmas. No es dudable que puede haber opiniones filosóficas de que se tiren consecuencias contra las doctrinas reveladas, y así se debe corregir la temeraria presunción de aquellos que, con el título de estar el objeto de la Filosofía sujeto al imperio de la razón, pretenden una libertad sin límites en el filosofar. Pero el empeño en que todos se ponen de que la filosofía que impugnan está mal avenida con lo que dicta la fe, muestra que en esto se procede con el mismo motivo de algunos príncipes que siempre que hallan escotadura para ello, hacen en sus manifiestos la guerra que emprenden causa de Religión" "(38).

Fr. Benito Feijóo, en resumen, pudo haber adoptado como lema estos versos de un poeta alemán de hoy: "No digáis nunca: esto es natural, para que nada pase por inmutable». Casi todos los saberes de su tiempo desfilaron ante sus ojos críticos, y no le arredró la espesa capa de ignorancia y mala intención que le fué preciso remover. Con un esfuerzo titánico acometió la corrección del torcido curso que a la cultura patria imprimió el último y delirante barroco. Necesitó para ello vigor, furia casi. Y no bajó su cerviz más que ante las doctrinas reveladas. De ahí su posición singular en tantos y tantos problemas, y los intentos fallidos de cuantos han pretendido encasillarlo. Quienes, por ejemplo, en estética, vayan a buscar en él un reflejo de las doctrinas clasicistas francesas, hallarán sólo desprecio por las reglas y fe

38. Itid... 11, 12, 19, 20. 
por el impetus sacer como motor poético. De ahí el error de cuantos hablan de un Feijóo prerromántico, interpretándolo desde el neoclasicismo, esto es, desde la esclavitud artística que había de sucederle... y atacarle. De igual modo, quienes esperen hallar en sus obras una defensa del casticismo y del purismo ambientes, en materia lingüística, tropezarán de pronto con hirientes galicismos y con esta irritada afirmación: "Los que a todas [voces] peregrinas niegan la entrada en nuestra locución llaman a esta austeridad pureza de la lengua castellana... ¡Pureza! Antes se deberá llamar pobreza, desnudez, miseria, sequedad" ${ }^{(39)}$. En este sentido, Feijóo llevó el espíritu del siglo de las luces mil veces más lejos que los avanzados "filósofos" ultramontanos, los cuales, si condujeron su pensamiento a más arriesgadas aventuras, doblegaron en cambio su audacia a las exigencias literarias y estilísticas del clasicismo francés.

Fr. Benito no toleraba beaterías científicas, filosóficas ni estéticas. Allá donde hubiera una verdad de general consenso, una limitación, podía haber un error. Hasta debajo del amor a la patria cabían solapadas añagazas, mezquinos intereses, capciosidad y engaño, y, por ello no tuvo inconveniente en ponerlo en entredicho, en otro de esos discursos suyos que promueven la perplejidad del lector ${ }^{(40)}$. Sin embargo, por una de esas raras paradojas que impone la historia, hemos de llamar a ese escepticismo patriótico de Feijóo y a su campaña contra las más arraigadas creencias de los españoles de su tiempo, patriotismo de la más alta calidad. Porque es patriota quien acierta a dotar a su país de lo

39. Cfr. F. Lázaro, op, eit, pg, 259 y ss.

40. Es el titulado Amor de la Patria y pasión nacional, TC. III, disc. X. Vtase la bella glosa y corrección que al escepticismo feijoniano puso R. Pérez de Ayala, Politica y toros, Madrid. Renacimiento, 1925, pg. $19 \mathrm{y} \mathrm{ss.}$ 
que precisa, aunque para ello tenga que hundir en él su lanceta.

$Y$ tornemos, en este punto final a aquel cotejo entre Fr. Benito Feijóo y Diego de Torres Villarroel que, al principio de nuestra disertación dejamos abierto. El famoso doctor Torres era, lo vemos claro ahora, una extraña supervivencia del siglo XVII, con sus magias, con su desarreglo, con sus gustos y con su estilo. Se iniciaba en él un extraño maridaje entre el nuevo y el viejo espíritu, entre el barroco y las luces, que no podía prosperar, porque para ello eran necesarios unos previos deslindes entre naturaleza y sobrenaturaleza, y la aplicación de un método, la experiencia, cosas todas ellas que pugnaban contra la esencia de lo barroco. La enemistad y oposición entre Torres y el benedictino, entre el mago y el científico, se nos aparece como el símbolo de la batalla entre el viejo y el nuevo siglo, y la clara victoria de este último representa la incorporación de España a Europa. Triunfó, pues, el espíritu de las luces, pero no a ultranza, sino copiosamente matizado, desde su españolidad y su cristianismo, por aquel luminoso modelo de prudencia y ejemplo inolvidable de sabiduría que fué Benito Jerónimo Feijóo y Montenegro. 